UNIVERSIDADE DE BRASILIA

FUP - Faculdade UnB Campus Planaltina

Gestão do Agronegócio

\title{
A UTILIZAÇÃO DO MODELO DE CUSTEIO VARIÁVEL APLICADO A UM EMPREENDIMENTO DE TURISMO RURAL: ESTUDO DE CASO NO HOTEL FAZENDA E PESQUE-PAGUE SOL NASCENTE - PLANALTINA/DF
}

Valdemar Onofre Neto

Planaltina - DF 
Valdemar Onofre Neto

\section{ANÁLISE DO CUSTEIO VARIÁVEL DO HOTEL FAZENDA E PESQUE-PAGUE SOL NASCENTE - UM COMPARATIVO ENTRE OS MESES DE OUTUBRO E NOVEMBRO DE 2011}

Trabalho realizado por Valdemar Onofre Neto junto a Universidade de Brasília (UnB) campi Planaltina (FUP), como pré-requisito para formação em Bacharel em Gestão do Agronegócio, sob orientação do Prof. Msc. William Santana.

Planaltina, Distrito Federal 2011 


\section{AGRADECIMENTOS}

Em primeiro lugar agradeço a Deus por ter me dado saúde e força para poder concluir este curso.

À minha mãe, Maria Helena Queiroz Onofre, pelo apoio incondicional, carinho, confiança e pelas palavras de motivação.

Aos meus avós, Valdemar Onofre e Lanyr Queiroz Onofre, pela ajuda, motivação e orações dedicadas a momentos difíceis.

Ao professor Msc. William Santana pelo apoio e cordialidade que resultaram na elaboração deste projeto. 
"Eu vou deixar meu endereço, ficareifeliz se alguém me visitar, a minha casa não tem luxo, porém quando ralear o mato, por favor tire o sapato pra passar no ribeirão, lá não tem água encanada, não tem farol de parada, nem tão pouco contramão, a grama verde é o tapete da chegada onde o vento passa agitando a paineira como se fosse uma bandeira hasteada em meu quintal, não bata forte ao passar pela porteira, que a pancada da madeira machuca o meu coração, lembro a batida que a morena deu na despedida, fazendo da minha vida, morada da solidão."

Autor desconhecido 


\section{RESUMO}

O presente relatório feito durante o estágio no Hotel Fazenda e Pesque-Pague Sol Nascente com início em agosto de 2011. Este trabalho teve como objetivo geral verificar a utilização do modelo de custeio variável em um empreendimento rural com a utilização de uma metodologia de estudo de caso com enfoque disciplinar através da coleta de dados por meio da técnica de observação participante. Como resultado podemos conhecer a real lucratividade da empresa através da determinação do custeio variável das atividades, uma vez separando os custos de cada uma. Este trabalho proporciona aos proprietários do empreendimento uma análise mais aprofundada com a finalidade de se determinar uma redução nos custos fixos para um aumento real na lucratividade da empresa.

Palavras-chave: Estudo de caso, hotel fazenda, métodos de custeio, custeio variável. 
SUMÁRIO

1 INTRODUÇÃO $\quad 8$

1.1 Caracterização da Organização e das Atividades do Estágio 9

1.1.1 O Conceito de Turismo Rural 9

$\begin{array}{lll}\text { 1.1.2 Estrutura Administrativa da Empresa } & 10\end{array}$

1.2 Situação Problema 13

1.3 Objetivos do Relatório $\quad 13$

1.3.1 Objetivo Geral 13

1.3.2 Objetivos Específicos 13

$\begin{array}{ll}1.4 \text { Justificativa } & 14\end{array}$

2 REFERENCIAL TEÓRICO

2.1 Métodos de custeio $\quad 15$

2.1.1 Custeio por absorção total 15

2.1.2 Custeio por absorção ideal 16

$\begin{array}{ll}\text { 2.1.3 Custeio variável } & 17\end{array}$

a) Custos fixos 18

b) Custos variáveis 19

c) Ponto de equilíbrio 19

d) Margem de contribuição 20

e) Grau de alavancagem operacional 20

3 ASPECTOS METODOLÓGICOS

3.1 A coleta de dados 23

4 ANÁLISE DOS RESULTADOS

5 CONSIDERAÇÕES FINAIS $\quad 28$

6 CRONOGRAMA DE ATIVIDADES DO ESTÁGIO 29

7 REFERÊNCIAS BIBLIOGRÁFICAS

$\begin{array}{ll}\text { ANEXOS } & 32\end{array}$ 


\section{ÍNDICE DE ILUSTRAÇÕES}

Figura 1 Esquema básico do custeio por absorção 16

Figura 2 Esquema básico do custeio variável

ÍNDICE DE TABELAS

TABELA 1 Custos fixos do Hotel Fazenda e Pesque-Pague Sol Nascente

TABELA 2 Custos variáveis do Hotel Fazenda e Pesque-Pague Sol Nascente

TABELA 3 Ponto de equilíbrio das atividades

TABELA 4 Margem de Contribuição por atividade

TABELA 5 Cronograma das atividades do estágio 


\section{1 - INTRODUÇÃO}

Atualmente vivemos em um mundo altamente competitivo, principalmente no âmbito empresarial, que não permite a sobrevivência de empresas desatualizadas e com pouco conhecimento e ineficiência de gestão. A qualificação e a informatização do sistema interno é indispensável para a tomada de decisões empresariais.

Controlar estoques e realizar a tomada de decisões baseando-se em anotações em papel é coisa do passado, haja visto que a informática está a disposição de todos, e deve ser usada nesse âmbito, pois anotações escritas podem conter erros, e se perder com o tempo.

A escolha de um sistema de informática e um modelo de custeio adequado as necessidades empresariais depende do tipo de negócio, da quantidade movimentada, e do que se pretende buscar dentro de uma empresa.

Diante destas informações, o presente trabalho representa as necessidades de controle financeiro encontradas no estágio realizado no Hotel Fazenda e Pesque-Pague Sol Nascente, realizado no período de agosto a dezembro de 2011.

A empresa inicia suas atividades financeiras e tomada de decisões baseadas em anotações em cadernos, porém sem um controle adequado de estoques, e financeiro, o que acabava por gerar despesas e outros problemas internos e externos no âmbito fiscal. A partir dessas informações foram elaboradas planilhas e métodos de controle e cálculos para a determinação do lucro líquido, que antes era desconhecido devido ao antigo modelo aplicado. 


\subsection{CARACTERIZAÇÃO DA ORGANIZAÇÃO E DAS ATIVIDADES DO ESTÁGIO}

\subsubsection{O Conceito de Turismo Rural}

De acordo com Uchôa (2009), o conceito de turismo rural está associado ao desenvolvimento de atividades complementares a propriedade rural, auxiliando na diversificação e aumento de renda, sem comprometer as atividades principais. Sendo assim, a atividade inicial do Centro de Lazer Sol Nascente era apenas a comercialização de peixes mediante o pesquepague, onde posteriormente a atividade hoteleira veio para complementar a renda da propriedade, não sendo tida como atividade principal.

Uchôa (2009) ainda complementa, inserindo a diferenciação entre os termos "Hotel Fazenda" e "Fazenda Hotel", onde o primeiro é referente a atividade hoteleira, similar a este ramo urbano, porém com suas instalações físicas na área rural, constituindo a atividade principal da propriedade.

Já o termo "Fazenda Hotel", é relacionado com uma propriedade rural que inicia as atividades hoteleiras como uma maneira de diversificar a renda da propriedade e o ramo de atividade, sem deixar as outras atividades de lado, sendo que o hotel não constitui a atividade principal da fazenda.

A empresa Hotel Fazenda e Pesque-Pague Sol Nascente é uma empresa de natureza familiar, do tipo sociedade limitada, registrada na Junta Comercial do Distrito Federal sob a Razão Social Centro de Lazer Sol Nascente Ltda, com o nome fantasia Hotel Fazenda e PesquePague Sol Nascente.

De propriedade dos irmãos Wilton Machado Irineu e Wilson Antônio Machado Irineu, a organização conta hoje com 24 colaboradores que trabalham em regime de 8 horas diárias durante 3 dias da semana. Quatro desses trabalhadores possuem vínculo empregatício com a empresa e vinte trabalham, como freelancers, mais especificamente nos finais de semana e feriados que são os dias abertos ao público. Além disso, a empresa conta com os serviços de um estagiário que se encarrega das seguintes atividades:

Controle de estoques;

Elaboração de balanços; 
Serviços de compras;

Controle da movimentação financeira;

Mensuração da lucratividade mensal da empresa.

Ainda sob a responsabilidade do estagiário está a aplicação do modelo de análise do custeio variável nos meses de outubro e novembro considerando aspectos ambientais e culturais da população do Distrito Federal.

A empresa está localizada na Fazenda Lagoa Bonita, Chácara Sol Nascente próximo ao centro de pesquisa Embrapa Cerrados e a Universidade UPIS, próximo ao Núcleo Rural Sarandi onde atende em média 200 clientes por semana.

\subsubsection{Estrutura Administrativa da Empresa}

O Hotel Fazenda e Pesque-Pague Sol Nascente inicia suas atividades no ano de 2000, inicialmente apenas como a exploração das atividades de pesca e fornecimento de refeições por meio de restaurante na propriedade. Nesse começo, pai e filho se revezavam na administração do empreendimento, realizando a aquisição de peixes para o abastecimento do pesqueiro por meio de terceiros, fazendo com que a propriedade nunca ficasse sem peixes em seus tanques.

A gestão familiar desenvolvida pelos proprietários se desenvolveu de maneira eficaz, atendendo as expectativas dos clientes, que aumentavam o consumo e o contingente a cada semana. Nesse momento, todo o processo administrativo e financeiro era controlado por meio de planilhas no programa Microsoft Excel, de maneira que era possível se descobrir a real lucratividade mensal do empreendimento, juntamente com a taxa de retorno de investimento, onde também era possível ter um controle total de estoques.

No ano de 2004, a propriedade contava com 4 funcionários registrados em carteira, e 16 freelancers, trabalhando de sexta-feira a domingo e feriados, divididos nas áreas dos bares, restaurante, atendimento e serviços gerais.

E como forma de melhorar a qualidade do atendimento dos clientes, os proprietários investiam na qualificação de seus funcionários através do investimento em cursos de qualidade 
no atendimento, oratória e técnicas de vendas ministrados pelo SEBRAE - DF na própria propriedade, sem nenhum ônus aos funcionários.

Porém, como os proprietários do empreendimento também possuíam uma fazenda de criação de gado no município de Araguaína, no estado do Tocantins, começavam a surgir dificuldades na administração dos dois negócios, uma vez tamanha a distância das duas localidades. Dessa maneira, com as duas propriedades se encontravam em pleno processo de desenvolvimento, os proprietários eram obrigados a percorrer uma distância de 1200 quilômetros em um intervalo máximo de 30 dias.

Foi então que os proprietários decidiram vender o Pesque-Pague Sol Nascente para investirem mais na criação de gado em Araguaína. A venda foi feita no ano de 2007 para dois irmãos que iniciavam suas atividades na área de turismo rural, haja visto a deficiência deste ramo no Distrito Federal.

Os atuais proprietários iniciaram as atividades do pesque-pague com o diferencial de possuírem um criatório de peixes, o que possibilitava a obtenção de peixes a um custo mais barato do que o do mercado, gerando assim mais economia nos custos da atividade.

Reconhecendo a necessidade de melhorias no setor de turismo rural do Distrito Federal, os proprietários decidiram então iniciar a construção de chalés para alugar para famílias passarem o final de semana junto à natureza. Foi então que foram construídos 20 chalés com infra-estrutura completa, piscina, sauna e churrasqueira, com capacidade de receber até 100 pessoas.

A partir de então, o pesqueiro ficou conhecido como Hotel Fazenda e Pesque-Pague Sol Nascente, e recebeu investimentos em todas as áreas, melhorias em locais que se encontravam precários para poder receber seus clientes oferecendo um serviço de qualidade agregado a uma excelente infra-estrutura.

A clientela cresce em grandes proporções, atraídas pelas melhorias ocorridas no pesqueiro, e também pela oportunidade de pernoite dentro da propriedade, seguidos de toda a atenção e atividades direcionadas aos hóspedes.

Além do ramo de turismo rural, os proprietários contam também com duas outras propriedades rurais, sendo uma destinada a criação de ovinos, e outra utilizada para a produção e comercialização de grama esmeralda, ambas com sua produção destinada ao mercado 
consumidor do Distrito Federal. Porém com tantos negócios diferentes e poucas pessoas na administração, começam a surgir os problemas.

O modelo de gestão destas empresas se remete ao conhecido modelo familiar, onde o surgimento de diferentes idéias e a inexistência de um consenso entre os membros da família é constante, ocasionando em uma administração de empresas deficiente.

Não obstante, o Hotel Fazenda e Pesque-Pague Sol Nascente passa também pelo problema da inexistência de um controle financeiro e de estoques dentro da propriedade, não podendo mensurar a lucratividade real do empreendimento, sem também conhecer o que foi consumido e o que ainda resta no estoque dentro da propriedade. 


\subsection{SITUAÇÃO PROBLEMA}

Como o modelo de custeio variável, aplicado a um empreendimento rural pode contribuir para a tomada de decisões.

\subsection{OBJETIVOS DO RELATÓRIO}

\subsubsection{OBJETIVO GERAL}

Verificar a utilização do modelo de custeio variável em um empreendimento rural.

\section{3..2 OBJETIVOS ESPECÍFICOS}

- Identificar os principais custos fixos e variáveis na empresa;

- Estabelecer critérios de rateio entre as atividades do empreendimento;

- Comparar os resultados de cada atividade;

- Analisar as principais decisões que podem ser tomadas a partir da aplicação do modelo de custeio variável. 


\subsection{JUSTIFICATIVA}

Este trabalho foi desenvolvido com a finalidade de estabelecer um método capaz de realizar o controle total das atividades financeiras e de estoques do Hotel Fazenda e PesquePague Sol Nascente, podendo assim conhecer a lucratividade real mensal do empreendimento, uma vez que atualmente na propriedade inexiste tal tipo de serviço.

De acordo com Souza (1999), atualmente não podemos iniciar um processo de tomada de decisões somente pelo "achismo", imaginando que porventura possa dar certo no futuro. A necessidade de informações que auxiliem na tomada de decisões é imprescindível para uma empresa, já que a falta delas ocasionará grandes prejuízos no futuro. Nesse momento, se faz indispensável um gerenciamento eficaz que atenda aos objetivos do negócio.

E, para que o processo gerencial tenha eficácia, é preciso um sistema de captação de informações que auxilie na tomada de decisões. Para isso, se faz necessário a implantação de um sistema de informações gerenciais para agilizar a tomada de decisões, uma vez que o atual sistema de controle feito se baseia em anotações em cadernos e folhas, sem nenhuma preocupação com o armazenamento de dados. 


\section{REFERENCIAL TEÓRICO}

\subsection{Métodos de Custeio}

Gagne e Discenza (1995) afirmam que os sistemas de custeio usados atualmente pelas empresas não fornece todas as informações necessárias para a tomada de decisões, fator limitante na ação da alta administração, sendo necessária a seleção de métodos alternativos que auxiliem todo o processo empresarial.

Dessa maneira, as empresas devem buscar um modelo aplicado as suas necessidades e que forneçam suporte à tomada de decisões e que seja condizente com o tipo de empreendimento trabalhado.

De acordo com Bornia (2002, apud Campagnolo, 2008) os sistemas de custeio apresentam três princípios básicos, compreendendo a absorção total, a absorção ideal e o custeio variável, que tratam os custos variáveis da mesma maneira, porém apresentam diferenças significativas na computação dos custos fixos.

\subsubsection{Custeio por Absorção Total}

Bornia (2002, apud Campagnolo, 2008) afirma que o princípio de absorção total apresenta a especificidade de dividir todos os gastos da empresa em parcelas absorvidas pelos produtos, distribuindo nesse caso, os custos totais empresariais. Este é um modelo de custeio aprovado pela legislação brasileira, usado não apenas para efeitos legais, mas também para o auxílio na tomada de decisões gerenciais.

Porém, para Campagnolo (2008) a principal desvantagem deste modelo é que ele não apresenta os custos unitários na obtenção de produtos, causando assim uma distorção que acaba gerando informações distorcidas no auxílio a tomada de decisões. Nesse modelo, o custo fixo independe do volume produzido, além de mensurar os gastos não contemplados em forma de perdas, como por exemplo ociosidade e refugos.

Já Segala e Silva (2007) enfocam que o princípio de custeio por absorção total deve ser usado para gerenciamentos que busquem a mensuração das perdas do processo de produção. 
Esta classificação possibilita ao gestor direcionar esforços para sanar tais problemas já que podem visualizar de forma distinta os pontos de correção, facilitando a atuação nestes. As perdas do processo ainda podem ser separadas em perdas por superprodução, transporte, processamento, fabricação de produtos defeituosos, movimento, espera, estoque e desperdício de matéria-prima (BORNIA,1995).

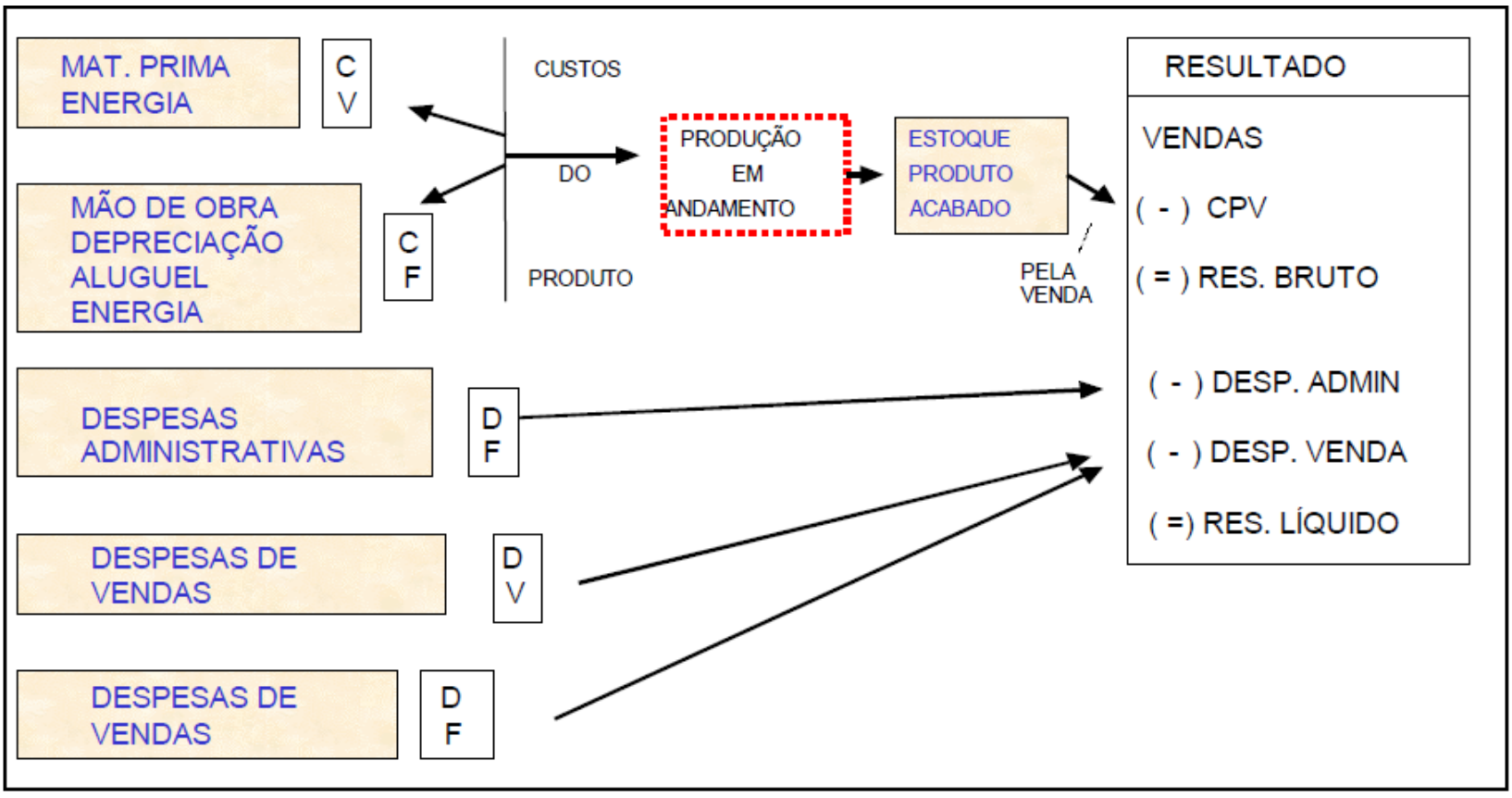

Figura 1: Esquema básico do custeio por absorção

Fonte: Silva e Miranda (2001, p.6)

\subsubsection{Custeio por Absorção Ideal}

Bornia (2002, apud Campagnolo, 2008) nos remete a idéia de que este modelo de custeio aloca todos os custos fixos e variáveis aos produtos, porém as perdas ocorridas não são repassadas aos produtos, sendo consideradas no geral como perdas do período. Isso ocorre porque para a elaboração do custo do produto, desconsidera-se o volume produzido e se analisam a capacidade de produção da organização.

Martins (1998) atenta que esse método de custeio apesar de ser um método tradicional usado nas empresas, não possui total confiabilidade para a determinação dos custos indiretos, uma vez exigida certa complexidade em computá-los. Dessa forma, os custos diretos são 
alocados aos produtos diretamente, enquanto os custos indiretos são distribuídos pelo sistema de rateio.

\subsubsection{Custeio Variável}

O custeio variável é usado para tomada de decisão de curto prazo, já que considera que apenas os custos variáveis incidem na elaboração do produto. Nesse caso, os custos fixos são tratados como despesas do período (SEGALA E SILVA, 2007).

Porém, Ponte, Riccio e Lustosa (2004) nos trazem a informação de que o custeio não é aceito pela legislação brasileira, na forma da lei no 6.404/76 (Lei das Sociedades Anônimas), nem pelo Imposto de Renda, e nem pelas Auditorias Externas devido ao fato de ferir princípios contábeis, como por exemplo o conflito entre despesas e receitas.

De acordo com este modelo de custeio, somente quando se determina a receita será possível fazer o abatimento dos custos de produção, ou seja, somente quando a produção for vendida será possível determinar os custos.

Em suma, como o modelo de custeio variável coloca os custos fixos como despesa sem analisar a quantidade vendida, afirma-se que ele viola este princípio. Mas mesmo que não seja aceito para demonstrações contábeis externas, não significa que não possa ser usado como ferramenta gerencial, e que no final da contabilização sejam feitos os ajustes necessários pela legislação brasileira.

Para Hendriksen (1965, p. 209), a maior vantagem do custeio variável é dar informações para a tomada de decisões aos administradores. Mas, como desvantagem, considera este princípio como sendo detentor de grande restrição no caso de suas proposições que são usadas como base para a análise dos ativos em diferentes situações. O uso do custeio variável permite a empresa encontrar a margem de contribuição, que representa a diferença entre a receita obtida pela venda dos produtos e a soma dos custos e despesas variáveis. 


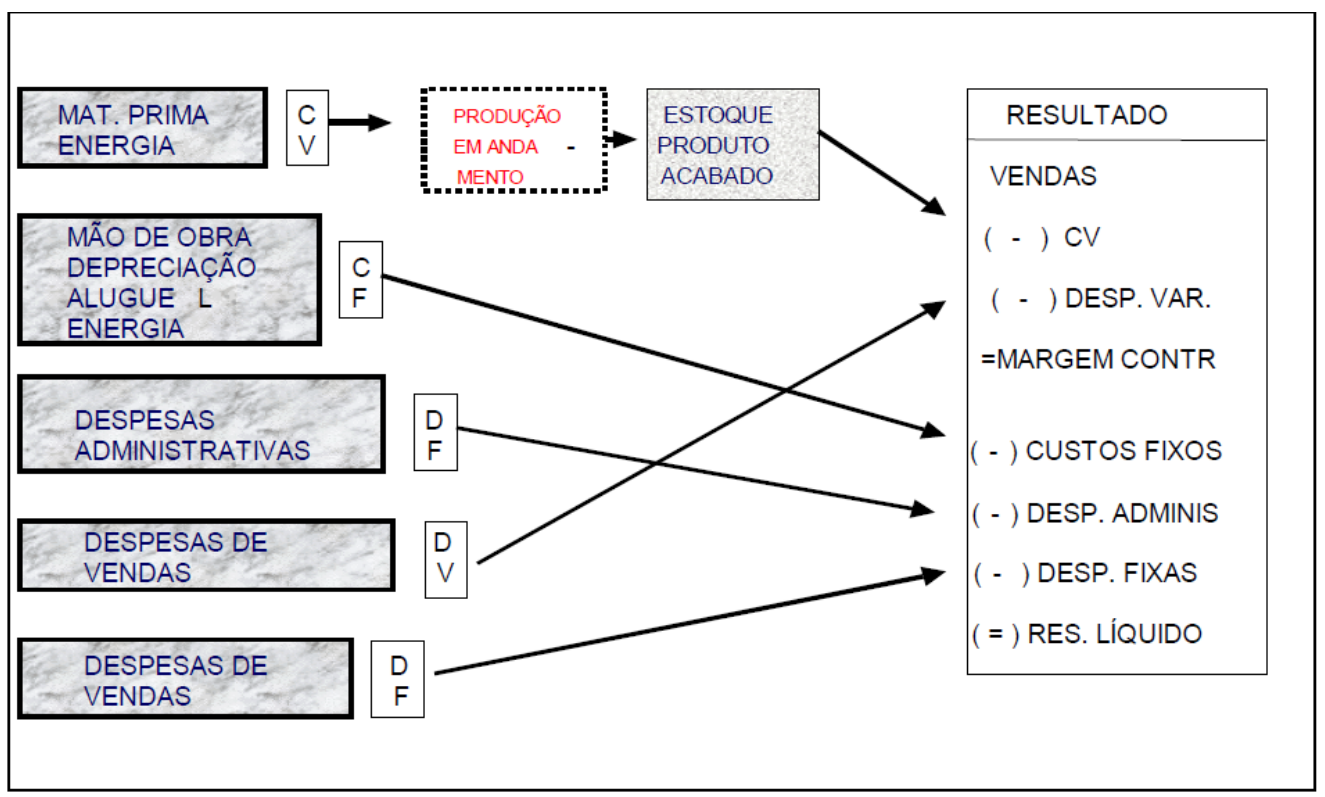

Figura 2: Esquema básico do custeio variável

Fonte: Silva e Miranda (2001, p.6)

a) Custos fixos

Segundo Martins (1998), os custos fixos empresariais são aqueles custos que não variam de acordo com a produção, ou seja, independentemente da quantidade de produtos ou serviços produzidos, os custos fixos serão os mesmos. Aplicando este conceito ao presente trabalho, os custos fixos da empresa estudada englobam:

Tabela 1: Custos fixos do Hotel Fazenda e Pesque-Pague Sol Nascente

\begin{tabular}{|r|r|}
\hline 2 Diaristas pesqueiro & Férias \\
\hline 2 Diaristas hotel & Honorários contador \\
\hline Gerente geral & Energia elétrica \\
\hline Gerente comercial & Ração cavalos/coelhos/aves \\
\hline Auxiliar de serv. Gerais & Ração peixes \\
\hline Jardineiro paisagista & Manutenção site \\
\hline FGTS funcionários efetivos & Divulgação Montreal Turismo \\
\hline Adiant. 13 salário & Tinta de impressora \\
\hline Piscineiro & Vigilante terceirizado \\
\hline Segurança monitorada & Imposto Territorial \\
\hline
\end{tabular}




\section{b) Custos variáveis}

Martins (1998) nos remete a idéia de que os custos variáveis são aqueles que variam de acordo com a quantidade de produtos e/ou serviços vendidos por uma empresa, nas mesmas proporções, ou seja, quanto maior as vendas, maior os custos e vice-versa. Trazendo para o presente estudo, os custos variáveis localizados dentro da propriedade, tanto na atividade hoteleira quanto no pesque-pague seguem da seguinte maneira:

Tabela 2: Custos variáveis do Hotel Fazenda e Pesque-Pague Sol Nascente

\begin{tabular}{|c|}
\hline Bebidas \\
\hline Diaristas do restaurante \\
\hline Materiais de limpeza \\
\hline Cielo cartões \\
\hline Eletricista \\
\hline Despesas com mercado \\
\hline Impostos sobre receita \\
\hline
\end{tabular}

c) Ponto de equilíbrio

De acordo com Lopes \& Carvalho (2002), o ponto de equilíbrio é determinado pela quantidade de produtos ou serviços que seja capaz de igualar os custos totais às receitas totais, não gerando lucro ou prejuízo. Neste caso, é a quantidade física de produtos e serviços do Hotel Fazenda e Pesque-Pague Sol Nascente que deveria ser comercializada para que o seu valor final fosse igual ao total de custos. Para o cálculo do ponto de equilíbrio de uma atividade, Martins (1998) determina a seguinte fórmula:

$$
\mathrm{Q}=\frac{\mathrm{CF}}{\mathrm{P}-\mathrm{CV}}
$$

Onde:

Q é a quantidade produzida; 
CF é o custo fixo total;

CV é o custo variável;

$\mathbf{P}$ é o preço de mercado do produto.

d) Margem de contribuição

Costa (2006) afirma que a margem de contribuição de um empreendimento pode ser definida como o produto da extração dos custos variáveis da receita total obtida com a venda de produtos e serviços. O resultado deste cálculo é a quantidade disponível para quitar os custos fixos e contribuir para o lucro operacional.

No caso do Hotel Fazenda e Pesque-Pague Sol Nascente, a análise foi feita dividida por atividades, podendo mensurar o percentual de margem de contribuição para cada atividade na obtenção do lucro. Para a determinação da margem de contribuição, segundo Martins (1998) usase o seguinte esquema:

\begin{tabular}{|l|}
\hline Preço (R\$) \\
\hline (x) Quantidade \\
\hline (=) Receita \\
\hline (-) Custos e despesas variáveis \\
\hline (=) Margem de Contribuição \\
\hline
\end{tabular}

e) Grau de Alavancagem Operacional - GAO

Segundo Warren (2001, p.113 apud COLODETI FILHO, GOMES E TEIXEIRA, 2003) a alavancagem operacional é usada para avaliar como uma possível alteração nas vendas pode alterar o lucro operacional, sem que para isso precise se realizar uma demonstração de resultados. Assim, uma alta alavancagem operacional pode indicar que um significativo aumento de vendas pode gerar um aumento atrativo no percentual do lucro operacional.

Dessa maneira, podemos entender que o grau de alavancagem operacional é a relação que pode existir das variações que acontecem no lucro operacional em função de variação no montante de vendas de determinada atividade. 
Para o cálculo do grau de alavancagem operacional, Dantas et al (2006) utiliza-se da seguinte fórmula:

$$
\mathrm{GAO}=\frac{\mathrm{X}(\mathrm{p}-\mathrm{V})}{\mathrm{X}(\mathrm{p}-\mathrm{V})-\mathrm{F}}=\frac{\mathrm{MC}}{\mathrm{LO}}
$$

Onde:

$\mathrm{X}=$ quantidade produzida e vendida

$\mathrm{P}=$ preço de venda

$\mathrm{V}=$ custo variável unitário

$\mathrm{F}=$ custos fixos 


\subsection{O Estado da Arte sobre o Custeio Variável}

Colauto, Beuren e Rocha (2004) afirmam que o modelo de custeio variável possibilitam a comparação entre os custos unitários, independentemente do volume de produção empresarial, possibilitando um melhor controle dos custos fixos, facilitando a análise custo-volume-lucro não alocando os custos fixos aos produtos pelo método de rateio. É muito utilizado no desenvolvimento de novos produtos e na tomada de decisões de curto prazo.

Nos estudos de Beuren (2003), fica confirmada a utilização do modelo de custeio variável em muitas empresas brasileiras, com a finalidade de se analisar o custo por unidade produzida. Porém como este modelo não é aceito para fins de legislação, é necessário que as empresas introduzam as alterações necessárias para fins legais, o que é feito sem complicações.

Zuccolotto e Colodeti Filho (2004) afirmam que o modelo de custeio variável é muito utilizado na tomada de decisões e conhecimento de preço unitário de produtos em supermercados, por apresentar os dados necessários a esta atividade. 


\section{ASPECTOS METODOLÓGICOS}

Caracterização do Estudo de Caso

Embora o estudo de caso corresponda a um tipo definido de pesquisa, pode assumir diferentes formatos (GIL, p.49), de acordo com os objetivos, do enfoque disciplinar, da quantidade de casos e das estratégias de coleta e análise de dados.

Em relação aos objetivos este trabalho classifica-se como descritivo pois procura identificar as múltiplas manifestações do fenômeno sob diversos olhares.

No enfoque disciplinar pode-se considerar este trabalho como um delineamento transdisciplinar por estar contido dentro das ciências sociais e aplicadas (gestão, administração e ciências contábeis).

No que diz respeito a quantidade de casos, tem-se um caso único porém de natureza exploratória pois os gestores da empresa esperam obter informações básicas para proporcionar um estudo mais aprimorado.

A coleta de dados para o estudo de caso segue técnicas múltiplas. Isto é importante para garantir a profundidade necessária ao estudo. Neste trabalho considerou-se os seguintes elementos para investigação: (1) o local em que ocorreu o fenômeno; (2) os atores envolvidos; (3) os eventos e (4) os processos.

\subsection{A Coleta de Dados}

A técnica de observação participante segundo Gil (1991) pode tomar a forma natural, onde o pesquisador é integrante do grupo pesquisado, convivendo de maneira amigável com o grupo ou a organização pesquisada. Nesse sentido, a coleta de dados foi realizada a partir de interação do pesquisador com o grupo pesquisado, nesse caso o Hotel Fazenda e Pesque-Pague Sol Nascente, de maneira que também foi realizada a pesquisa documental com acesso a dados restritos financeiros da empresa, com a finalidade de se buscar conhecer o custo variável e fixo de cada atividade desenvolvida dentro da empresa, e desenvolver propostas para uma gestão mais participativa e conhecedora da real importância do controle dos custos fixos e variáveis. 


\section{ANÁLISE DOS RESULTADOS}

A utilização do modelo de custeio variável permitiu um maior controle dos custos e despesas por cada uma das atividades desenvolvidas dentro do Hotel Fazenda e Pesque-Pague Sol Nascente, uma vez que antes o controle era feito considerando-se as receitas e despesas de uma maneira geral, impossibilitando os proprietários de conhecer os ganhos que cada atividade estaria proporcionando.

O controle de estoques inexistia anteriormente na empresa, gerando problemas de incapacidade de controle e ausência inexplicável de produtos, fato que desapareceu após a implantação do controle desenvolvido no período de estágio.

Como se trata de uma atividade de lazer no meio rural, podemos entender que a influência do clima é fator extremamente importante para o desenvolvimento da mesma, onde períodos ensolarados contribuem para o aumento da clientela, e conseqüentemente, para o aumento das vendas, principalmente de bebidas. Porém, ao contrário dessa premissa, os períodos chuvosos reduzem drasticamente a quantidade de freqüentadores, ocorrendo casos de dias muito chuvosos onde inexistem clientes na empresa.

Seguindo essa premissa e analisando o controle das planilhas, podemos perceber que o mês de outubro foi de grande contingente de pessoas, porque foi um mês com ausência de chuvas, o que possibilitou a empresa obter um lucro operacional de $\mathrm{R} \$ 73.195,87$ somando-se o lucro obtido em todas as atividades. No mês de outubro o Hotel Fazenda e Pesque-Pague Sol Nascente recebeu um contingente de 1662 clientes no pesque-pague e 369 hóspedes no hotel.

Já no mês de novembro, considerando que a meteorologia foi um pouco "cruel", trazendo chuvas em praticamente todos os dias de atividade do Hotel Fazenda e Pesque-Pague Sol Nascente, subentende-se que foi um mês pouco lucrativo, atingindo uma quantidade de 775

pessoas no pesque-pague e 72 hóspedes no hotel. Nota-se que é uma quantidade razoável de clientes, porém o consumo de produtos se reduz devido ao clima frio e chuvoso deste mês.

Mesmo assim, considerando os fatores climáticos, em uma análise de todas as atividades no geral, obteve-se um lucro operacional de $\mathrm{R} \$ 32.567,03$ no mês de novembro, o que se percebe uma redução de 38\% em relação ao mês de outubro de 2011. 
Atualmente o valor da entrada no pesque-pague é de $\mathrm{R} \$ 15,00$ por pessoa, fato que apresenta redução na quantidade de pessoas, uma vez que o público freqüentador é, em sua maioria, proveniente da cidade de Planaltina-DF e possui em sua maioria, pessoas das classes B e $\mathrm{C}$, de acordo com a renda obtida. Percebe-se uma quantidade de clientes de Brasília, porém estes em menor quantidade. O lucro obtido com as entradas, retirando-se os custos e despesas variáveis e fixas é alto, e capaz de quitar um possível saldo negativo gerado em outras atividades.

Retirando-se os custos fixos e variáveis, o lucro obtido com o pagamento das entradas no mês de outubro foi de $\mathrm{R} \$ 21.497,91$, e no mês de novembro já foi reduzido em $41 \%$ devido a fatores climáticos, porém fecha o mês com saldo positivo.

Nas atividades do hotel fazenda, o hóspede paga o valor de $\mathrm{R} \$ 140,00$ por uma diária incluindo-se café da manhã, almoço, jantar e acesso ao pesque-pague. Esta atividade possui altos custos fixos e inexiste uma demanda freqüente por este serviço, fato que gera prejuízo em alguns períodos do ano. Considerando o mês de outubro, o hotel fazenda obteve um montante de receitas de $\mathrm{R} \$ 51.660,00$ e posteriormente um lucro de $\mathrm{R} \$ 33.556,11$.

Dos R $\$ 140,00$ cobrados pela diária do hotel, $\mathrm{R} \$ 40,00$ destinam-se ao pagamento do almoço e jantar dos hóspedes, e analisando um cenário de se oferecer os serviços de hospedagem e de café da manhã sem contar as outras refeições, o hotel fazenda deixa de ganhar no mês de outubro cerca de $\mathrm{R} \$ 14.760,00$, o que implicaria redução no lucro da atividade hoteleira.

O hotel fecha o mês de novembro com saldo negativo d R\$ 2,265,63, devido ao fato da ausência de clientes, e, realizando a análise do cenário acima, sem o valor das demais refeições, o hotel fecharia o mês com um saldo devedor ainda maior, na casa dos $\mathrm{R} \$ 5.145,63$.

Percebe-se que o valor da diária de $\mathrm{R} \$ 140,00$ gera um saldo maior, onde contribui para a atividade do restaurante, onde sem a cobrança dos $\mathrm{R} \$ 40,00$ das refeições, o lucro seria menor, uma vez que os custos fixos do hotel e do restaurante são altos e existem independentemente da quantidade de clientes.

Quanto ao aluguel do auditório, este fecha com saldo negativo o mês de outubro, devido a inexistir a locação do mesmo neste período, e os custos fixos continuarem existindo no que se refere à manutenção e limpeza. Já no mês de novembro, houve locações para eventos, festas e 
casamentos que proporcionaram um lucro de $\mathrm{R} \$ 20.349,68$, o que proporcionou um equilíbrio nos prejuízos de algumas atividades no presente mês.

No que se refere à movimentação do pesque-pague, o mês de outubro foi altamente rentável devido ao fato da existência do fechamento de pacotes de grupos escolares e de igrejas, que ocasionalmente visitam o pesque-pague para eventos escolares e atividades religiosas durante a semana, em dias pré-determinados para uso exclusivo do grupo. Fato este que não foi visto no mês de novembro, onde as atividades fecham com um saldo $70 \%$ menor em relação ao mês anterior, porém ainda positivo.

Fazendo uma análise da pesca esportiva, percebemos que a mesma é pouco rentável para a empresa, dadas as despesas fixas e variáveis, trouxe um prejuízo operacional de $\mathrm{R} \$ 1.000,00$ no mês de outubro e um saldo negativo de $\mathrm{R} \$ 243,81$. Esta atividade poderia se tornar inviável e até ser descartada, mas nesse ramo de atividade, a pesca esportiva é considerada um hobby para muitos amantes da pesca, fato que ao acaso aparecem grupos de pescadores profissionais que se dedicam somente a esta atividade dentro do pesque-pague. Mesmo com uma pequena lucratividade dentro da empresa, a atividade de pesca esportiva deve ser melhorada e continuada dentro da empresa, uma vez que não apresentou resultados negativos.

Chegando a atividade de refeições por meio do restaurante, percebe-se também uma alta nos custos fixos e variáveis do mesmo, observando que os hóspedes contribuem para cerca de 20 a 30\% da receita total. Considerando as informações do mês de outubro, o restaurante fecha com um lucro de $\mathrm{R} \$ 312,40$, ou seja, um baixo lucro para um mês com grande quantidade de pessoas. Mas em relação ao mês de novembro, a empresa amarga um prejuízo de $\mathrm{R} \$ 3.494,83$ na atividade.

Percebe-se nesse momento uma análise minuciosa para se conhecer se realmente compensa esta atividade dentro da propriedade, ou se a terceirização não seria uma melhor maneira de economizar despesas.

De uma maneira geral, percebe-se uma grande diferença de receitas entre os meses analisados, o que não pode ser considerado totalmente, exigindo para esta pesquisa uma análise com pelo menos 6 meses do ano, com a finalidade de se analisar diferentes cenários com diferentes fatores de aumento e redução de custos, e com diferentes quantidades de clientes. 
O Hotel Fazenda e Pesque-Pague Sol Nascente encerra suas atividades no mês de outubro com um lucro operacional de $\mathrm{R} \$ 73.495,87$ sendo que obteve um pequeno prejuízo nas atividades de aluguel do auditório na casa dos $\mathrm{R} \$ 643,07$ e na pesca esportiva, de $\mathrm{R} \$ 1.004,86$ que pôde ser quitada com o lucro das outras atividades sem maiores prejuízos.

Já o mês de novembro foi um pouco mais complicado, devido a ter apresentado prejuízo operacional nas atividades do hotel, pesca esportiva e restaurante, totalizando um saldo negativo de $\mathrm{R} \$ 6.004,26$. Porém as demais atividades apresentaram um lucro operacional de $\mathrm{R} \$ 32.567,03$, sendo que mais de $80 \%$ dessa receita foi obtida com o aluguel do auditório, que é muito procurado no final do ano devido a grande quantidade de festas existentes nessa época.

Retirando-se o prejuízo operacional, podemos ver que este mês fecha com saldo positivo de $\mathrm{R} \$ 26.507,57$, ou seja, o lucro das demais atividades quita o prejuízo das 3 atividades negativas sem comprometer o resultado final obtido pela empresa.

Aplicando o conceito de ponto de equilíbrio, podemos observar que o mesmo é explicitado por cada atividade da seguinte forma:

Tabela 3: Ponto de equilíbrio das atividades do Hotel Fazenda e Pesque-Pague Sol Nascente

\begin{tabular}{|l|l|l|l|l|l|l|}
\hline & \multicolumn{6}{|c|}{ ATIVIDADES } \\
\hline & Entradas & Hotel & Auditório & Pesque-pague & Pesca esportiva & Restaurante \\
\hline Ponto de equilíbrio & 229 pessoas & 130 diárias & 1 locação & $R \$ 22.690$ & 114 pessoas & 1110 refeições \\
\hline
\end{tabular}

Reconhecendo também a importância da margem de contribuição empresarial, segue a tabela com a diferença entre a margem dos meses de outubro e novembro:

Tabela 4: Margem de contribuição por atividade

\begin{tabular}{|c|c|c|c|c|c|c|c|c|c|}
\hline \multicolumn{10}{|c|}{ MARGEM DE CONTRIBUIÇÃO POR ATIVIDADE } \\
\hline MÊS & Entradas & Hotel & Aud & ório & Pesc & 1e-pague & Pesc & portiva & Restaurante \\
\hline Outubro & R\$ 24.930,00 & $\mathrm{R} \$ 40.935,57$ & $-R \$$ & 417,47 & $\mathbf{R} \$$ & $25.960,11$ & $\mathbf{R} \$$ & 745,14 & $\mathrm{R} \$ \mathbf{3 . 7 4 3 , 8 2}$ \\
\hline Novembro & $\mathrm{R} \$ 11.625,00$ & $\mathrm{R} \$ \quad 5.113,84$ & $\mathbf{R} \$$ & $20.575,28$ & $\mathbf{R} \$$ & $11.008,70$ & $\mathbf{R} \$$ & $1.506,19$ & 63,40 \\
\hline
\end{tabular}




\section{CONSIDERAÇÕES FINAIS}

Analisando o Hotel Fazenda e Pesque-Pague Sol Nascente durante o período de estágio e com o auxílio da interpretação de dados financeiros, podemos observar que a empresa possui um grande potencial de crescimento, haja vista a estrutura física que a mesma possui. Porém existem algumas considerações a ser feitas, cabendo uma análise mais específica de cada uma das propostas por parte dos proprietários para entender a possibilidade destas mudanças.

O valor da entrada, hoje é de $\mathrm{R} \$ 15,00$, o que faz com que a clientela seja mais proveniente das classes A e B, e em sua grande maioria residentes em Brasília-DF, o que não deixa de ser interessante porque é um público que não se preocupa muito com gastos, e sim qualidade nos serviços. Porém a distância da propriedade até Brasília (cerca de $40 \mathrm{~km}$ ) interrompe o fluxo de pessoas deste local, trazendo atualmente apenas clientes com fidelidade com a empresa, o que não ocasiona uma quantidade significativa de pessoas nos dias de funcionamento.

Já o público de Planaltina-DF possui baixo poder aquisitivo, uma vez esta ser uma cidade considerada de periferia, e possuindo poucos locais de lazer aos seus moradores. Percebe-se então, que o valor praticado pelo empreendimento é superior aos demais locais de lazer da cidade de Planaltina-DF, sendo que se este fosse reduzido, aumentaria a quantidade de pessoas que moram próximo do estabelecimento, e conseqüentemente aumentaria a renda obtida nas atividades da empresa.

De uma maneira geral, percebe-se que o Hotel Fazenda e Pesque-Pague Sol Nascente é uma empresa com alto potencial de lucratividade em decorrência da localização e da estrutura física que o compõe. Porém a gestão se encontra deficitária em determinados momentos, o que acaba aumentando demasiadamente os custos fixos da empresa, reduzindo assim o lucro obtido.

Com uma boa gestão e um controle financeiro informatizado e com qualidade, é possível que a empresa venha a gerar lucros em um curto período de tempo, uma vez que o gasto com a divulgação é alto, e está sendo feito com sucesso, pois muitas pessoas novas têm visitado a propriedade nos finais de semana. Existe a necessidade de uma participação integrada dos proprietários e funcionários da empresa, pois se trata de uma empresa familiar e todos devem contribuir para a geração de lucros. 


\section{CRONOGAMA DE ATIVIDADES}

O período de estágio no Hotel Fazenda e Pesque-Pague Sol Nascente teve duração de 3 meses e 10 dias, iniciando-se no dia 22 de agosto de 2011 e com término na data de 01 de dezembro de 2011, compreendendo um total de 300 horas de atividades.

A seguir, apresenta-se as atividades desenvolvidas em cada um dos meses de estágio dentro da empresa:

Tabela 5: Cronograma de atividades do estágio

\begin{tabular}{|c|c|c|c|c|}
\hline \multicolumn{5}{|c|}{ MÊS } \\
\hline & AGOSTO & SETEMBRO & OUTUBRO & NOVEMBRO \\
\hline \multirow{4}{*}{ ATIVIDADES } & $\begin{array}{l}\text { Início das } \\
\text { atividades }\end{array}$ & \begin{tabular}{l}
\multicolumn{2}{l}{ Desenvolvimento do } \\
sistema de controle \\
financeiro \\
programa Excel; no
\end{tabular} & $\begin{array}{ll}\text { Início } & \text { da } \\
\text { entrada } & \text { de } \\
\text { dados } & \text { no } \\
\text { sistema; } & \end{array}$ & $\begin{array}{l}\text { Controle total das } \\
\text { movimentações } \\
\text { financeiras; }\end{array}$ \\
\hline & $\begin{array}{l}\text { Análise da } \\
\text { gestão } \\
\text { financeira; }\end{array}$ & 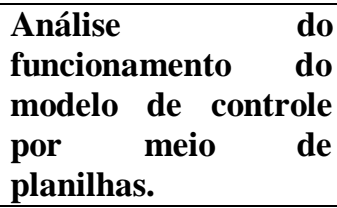 & $\begin{array}{lr}\text { Controle } & \text { de } \\
\text { entradas } & \text { e } \\
\text { saídas } & \\
\text { financeiras } & \text { no } \\
\text { programa; } & \end{array}$ & $\begin{array}{l}\text { Análise financeira } \\
\text { por atividade; }\end{array}$ \\
\hline & $\begin{array}{lr}\text { Escolha } & \text { do } \\
\text { modelo } & \text { de } \\
\text { custeio a } & \text { ser } \\
\text { adotado; } & \end{array}$ & & $\begin{array}{l}\text { Análise } \\
\text { financeira por } \\
\text { atividade com } \\
\text { a aplicação do } \\
\text { modelo de } \\
\text { custeio } \\
\text { variável. }\end{array}$ & $\begin{array}{l}\text { Análise comparativa } \\
\text { entre a } \\
\text { movimentação dos } \\
\text { meses de outubro e } \\
\text { novembro; }\end{array}$ \\
\hline & & & & $\begin{array}{l}\text { Apresentação dos } \\
\text { resultados e término } \\
\text { do estágio }\end{array}$ \\
\hline
\end{tabular}




\section{REFERÊNCIAS BIBLIOGRÁFICAS}

BEUREN, Ilse Maria; SOUSA, Marco Aurélio Batista de; RAUPP, Fabiano Maury. Um estudo sobre a utilização de sistemas de custeio em empresas brasileiras. In: CONGRESSO INTERNACIONAL DE CUSTOS - CIC, Punta del Este, Uruguay, 2003. Anais... Disponível em: http://www.iem.efei.br/edson/download/Congresointernacional2004/110sistemasdecusteiobr asilsurvey.doc>. Acesso em: 04 dez. 2011.

BORNIA, A.C.; Mensuração das Perdas dos Processos Produtivos: Uma Abordagem Metodológica de Controle Interno. Tese de Doutorado em Engenharia de Produção, Universidade Federal de Santa Catarina, Florianópolis, 1995.

BORNIA, A.C.; Análise Gerencial de Custos. Aplicação em Empresas Modernas. Porto Alegre: Bookmann, 2002. In: CAMPAGNOLO, R.R.; Proposta para uma Sistemática para Redução de Custos apoiada a Metodologia do Custeio-Alvo: Um caso do Setor Hoteleiro. Porto Alegre, 2008.

CAMPAGNOLO, R.R.; Proposta para uma Sistemática para Redução de Custos apoiada a Metodologia do Custeio-Alvo: Um caso do Setor Hoteleiro. Porto Alegre, 2008.

COLAUTO, R. D.; BEUREN, I. M., ROCHA, W. O custeio variável e o custeio-alvo como suporte às decisões de investimentos no desenvolvimento de novos produtos. Base, v. 1 n. 2 , 2004.

COSTA, G.A.A. Modelo de margem de contribuição aplicado ao planejamento de marketing no transporte marítimo regular de contêineres. 264p. Dissertação (Mestrado) Departamento de Engenharia Naval. Escola Politécnica da Universidade de São Paulo. São Paulo, 2006.

DANTAS, José Alves; MEDEIROS, Otávio Ribeiro de; LUSTOSA, Paulo Roberto B.

Reação do Mercado à Alavancagem Operacional: um Estudo Empírico no Brasil. Revista Contabilidade e Finanças - USP, São Paulo, n. 41, p. 72-86, Maio/Ago. 2006.

GAGNE, M.L.; DISCENZA,R. Target Costing. Journal of Business \& Industrial Marketing, v.10, n.1, p.16-22, 1995.

GIL, Antonio Carlos. Como elaborar projetos de pesquisa. São Paulo: Atlas, 1991. 
GIL, Antonio Carlos. Métodos e técnicas de pesquisa social. São Paulo: Atlas, 1999.

HENDRIKSEN, Eldon S.. Accounting theory. 4. ed. Homewood: Irwin, 1965.

LOPES, M. A.; CARVALHO, F. de M. Custo de produção do gado de corte. Lavras: UFLA, 2002. 47 p. (Boletim Agropecuário, 47).

MARTINS, Eliseu. Contabilidade de Custos. 6. Ed. São Paulo: Atlas. 1998.

ORNSTEIN, Rudolf. Alocação dos custos centrais. Conselho Regional de Contabilidade, 1980.

PONTE, V. M. R.; RICCIO, E. L.; LUSTOSA, P. R. B. (2004) - Uma Análise Comparativa entre a "Contabilidade de Ganhos - Throughput Accounting" e o "Método do Custeio Variável". Disponível em: <http://www.eac.fea.usp.br/eac/publicacoes/artigos.asp>. Acesso em: 05 dez. 2011.

SEGALA, Cristiane Z. S.; SILVA, Ivanir T. da. Apuração dos custos na produção de leite em uma propriedade rural do município de Irani-SC. Concórdia. Disponível em:〈http://www.custoseagronegocioonline.com.br/numero1v3/Custos\%20do\%20leite.pdf > Acesso em: 06 dez. 2011.

SILVA, J. D. G.; MIRANDA, L. C. O controle de custos e o processo gerencial na indústria hoteleira do nordeste brasileiro: Um estudo da realidade gerencial hoteleira em face da nova dinâmica competitiva do setor. In: CONGRESO LATINO AMERICANO DE ESTRATÉGIA, 14. 2001, Buenos Aires.

SOUZA, Ricardo Guimarães. Desenvolvimento do Sistema de Implantação e Gestão da Manutenção. UFRS, Porto Alegre, 1999. Disponível em: <www.lume.ufrgs.br/bitstream/handle/10183/2182/000270097.pdf?sequence=1 >.Acesso em: 18 set. 2011.

WARREN, Carl S.; REEVE, James M.; FESS, Philip E. Contabilidade gerencial. $6^{\text {a }}$ ed. São Paulo: Pioneira Thomson Learning; 2001.In: COLODETI FILHO, E.; GOMES, Carlos E.A.; TEIXEIRA,A.J.C.Uma reflexão sobre a segregação dos custos com o uso da análise de regressão linear: o caso da Espírito Santo Borrachas.

ZUCCOLOTTO, Robson; COLODETI FILHO, Érico. Gerenciamento de preços em empresas de pequeno porte por meio do custeio variável e do método de Monte Carlo. São Paulo: Congresso USP, 2004. 
ANEXO 1: Planilha de controle financeiro por atividade do mês de outubro de 2011

CONTROLE FINANCEIRO OUTUBRO/2011

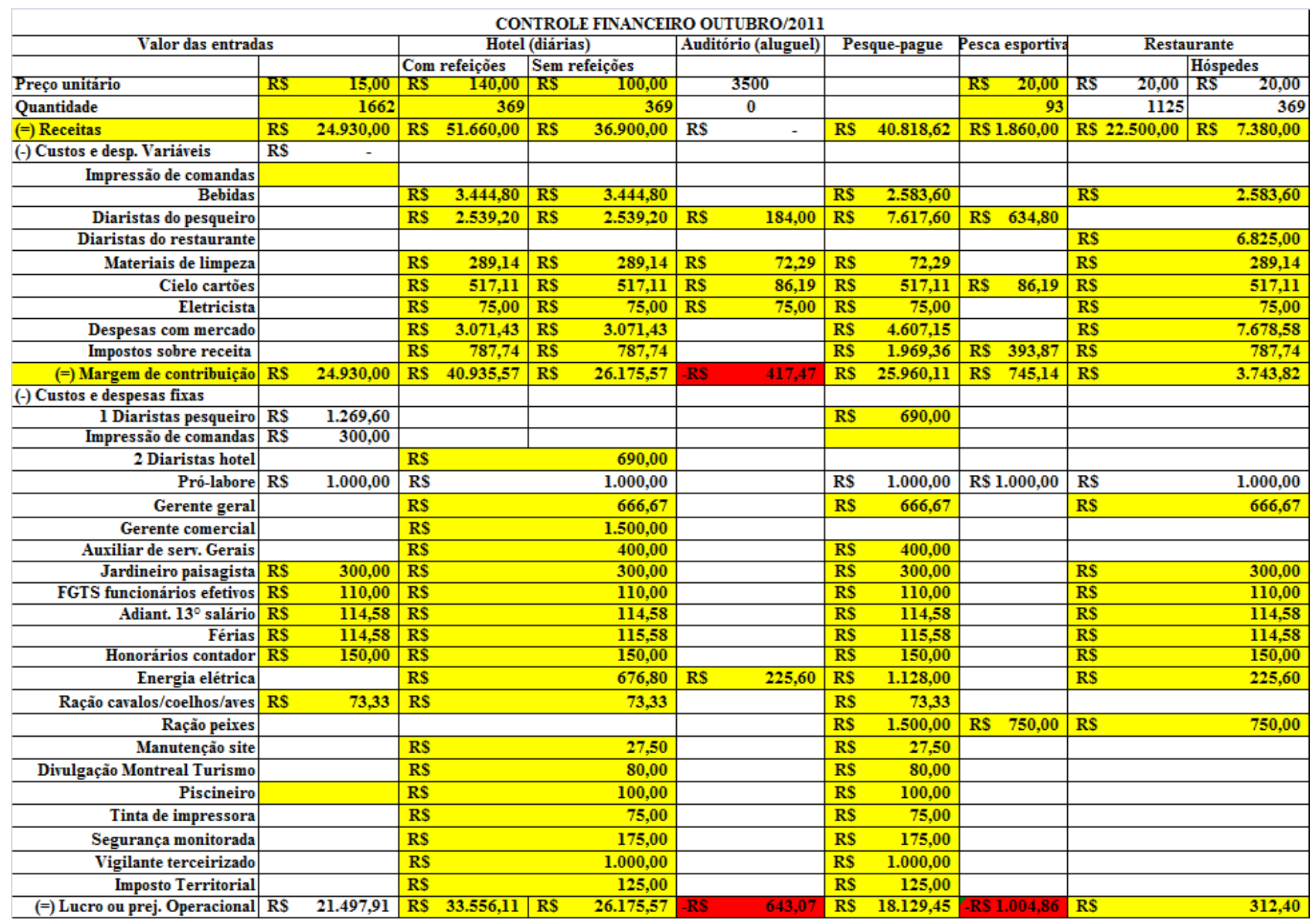


ANEXO 2: Planilha de controle financeiro por atividade do mês de novembro de 2011

CONTROLE FINANCEIRO NOVEMBRO/2011

\begin{tabular}{|c|c|c|c|c|c|c|c|c|c|c|c|c|}
\hline \multicolumn{3}{|c|}{ Valor das entradas } & \multicolumn{3}{|c|}{ Hotel (diárias) } & Auditório (aluguel) & \multirow{2}{*}{\multicolumn{2}{|c|}{ Pesque-pague }} & \multicolumn{2}{|c|}{ Pesca esportiva } & \multicolumn{2}{|c|}{ Restaurante } \\
\hline & & & \multicolumn{2}{|c|}{ Com refeições } & Sem refeições & & & & & & & Hóspedes \\
\hline Preço unitário & R\$ & 15,00 & RS & 140,00 & 100,00 & & & & R\$ & 20,00 & 20,00 & 20,00 \\
\hline Quantidade & & 775 & & 72 & 72 & & & & & 100 & 508 & 72 \\
\hline \multirow[t]{2}{*}{$(=)$ Receitas } & RS & $11.625,00$ & RS & $10.080,00$ & $7.200,00$ & $21.000,00$ & RS & $17.058,88$ & RS & $2.000,00$ & RS $10.160,00$ & RS $1.440,00$ \\
\hline & & & & & & & & & & & R\$ & $11.600,00$ \\
\hline \multicolumn{13}{|l|}{ (-) Custos e desp. Variáreis } \\
\hline Bebidas & & & RS & $1.985,60$ & $1.985,60$ & & & & & & RS & $2.978,40$ \\
\hline Diaristas do pesqueiro & & & R\$ & 956,80 & 956,80 & 184,00 & R\$ & $2.870,40$ & RS & 239,20 & & \\
\hline Diaristas do restaurante & & & & & & & & & & & R\$ & $4.940,00$ \\
\hline Materiais de limpeza & & & RS & 110,80 & 110,80 & 27,70 & RS & 27,70 & & & RS & 110,80 \\
\hline Cielo cartões & & & RS & 196,89 & 196,89 & 32,82 & R\$ & 196,89 & R\$ & 32,82 & RS & 196,89 \\
\hline Eletricista & & & RS & 125,00 & 125,00 & 125,00 & R\$ & 125,00 & & & R\$ & 125,00 \\
\hline Despesas com mercado & & & RS & $1.147,49$ & $1.147,49$ & & R\$ & $1.721,24$ & & & RS & $2.868,73$ \\
\hline Impostos sobre receita & & & RS & 443,58 & 443,58 & & RS & $1.108,95$ & RS & 221,79 & RS & 443,58 \\
\hline$(=)$ Margem de contribuição & RS & $11.625,00$ & RS & $5.113,84$ & $2.233,84$ & $20.630,48$ & RS & $11.008,70$ & RS & $1.506,19$ & -RS & 63,40 \\
\hline \multicolumn{13}{|c|}{\begin{tabular}{l|l}
$(-)$ Custos e despesas fixas & \\
\end{tabular}} \\
\hline 1 Diaristas pesqueiro & RS & 478,40 & & & & & R\$ & 690,00 & & & & \\
\hline 2 Diaristas hotel & & & R\$ & & 690,00 & & & & & & & \\
\hline Pró-labore & R\$ & $1.000,00$ & R\$ & & $1.000,00$ & & R\$ & $1.000,00$ & R\$ & $1.000,00$ & R\$ & $1.000,00$ \\
\hline Impressão de comandas & R\$ & 300,00 & & & & & & & & & & \\
\hline Gerente geral & & & RS & & 666,67 & & RS & 666,67 & & & R\$ & 666,67 \\
\hline Gerente comercial & & & RS & & $1.500,00$ & & & & & & & \\
\hline Auxiliar de serv. Gerais & & & RS & & 400,00 & & RS & 400,00 & & & & \\
\hline Jardineiro paisagista & RS & 300,00 & RS & & 300,00 & & RS & 300,00 & & & RS & 300,00 \\
\hline FGTS funcionários efetivos & RS & 110,00 & RS & & 110,00 & & RS & 110,00 & & & RS & 110,00 \\
\hline Adiant. $13^{\circ}$ salário & R\$ & 114,58 & R\$ & & 114,58 & & R\$ & 114,58 & & & R\$ & 114,58 \\
\hline Férias & RS & 114,58 & RS & & 115,58 & & R\$ & 115,58 & & & R\$ & 114,58 \\
\hline Honorários contador & RS & 150,00 & R\$ & & 150,00 & & R\$ & 150,00 & & & RS & 150,00 \\
\hline Energia elétrica & & & RS & & 676,80 & 225,60 & R\$ & $1.128,00$ & & & R\$ & 225,60 \\
\hline Ração cavalos/coelhos/aves & RS & 73,33 & RS & & 73,33 & & R\$ & 73,33 & & & & \\
\hline Ração peixes & & & & & & & RS & $1.500,00$ & RS & 750,00 & RS & 750,00 \\
\hline Manutenção site & & & RS & & 27,50 & & R\$ & 27,50 & & & & \\
\hline Divulgação Montreal Turismo & & & R\$ & & 80,00 & & R\$ & 80,00 & & & & \\
\hline Piscineiro & & & RS & & 100,00 & & R\$ & 100,00 & & & & \\
\hline Tinta de impressora & & & R\$ & & 75,00 & & R\$ & 75,00 & & & & \\
\hline Segurança monitorada & & & R\$ & & 175,00 & & R\$ & 175,00 & & & & \\
\hline Vigilante terceirizado & & & R\$ & & $1.000,00$ & & R\$ & $1.000,00$ & & & & \\
\hline Imposto Territorial & & & RS & & 125,00 & & R\$ & 125,00 & & & & \\
\hline (=) Lucro ou prej. Operacional & RS & $8.984,11$ & -RS & $2.265,63$ & $5.145,63$ & $20.404,88$ & RS & $3.178,04$ & $-\mathrm{RS}$ & 243,81 & $-\mathrm{RS}$ & $3.494,83$ \\
\hline
\end{tabular}

